\title{
Filling patterns in contrast ventriculography
}

\author{
LAWRENCE FERGUSON ${ }^{1}$ \\ From the Division of Neurosurgery, Institute of Neurological Sciences, \\ Southern General Hospital, Glasgow
}

SYNOPSIS The filling patterns of a negative contrast material (air), a positive contrast water soluble material (Conray), and a positive contrast water insoluble material (Myodil) were examined in 60 normal ventriculograms. Using a scoring system developed for this study, Conray was found effective for outlining the ipsilateral (injected) lateral ventricle, the third ventricle, the aqueduct of Sylvius, and the fourth ventricle. Air was the most effective for the noninjected lateral ventricle, while Myodil was best for A-P demonstration of the aqueduct. The clinical implications of these findings are discussed.

Now that angiography is the basic neuroradiological investigation in most clinics, ventriculography is more commonly reserved for accurate definition of specific regions either for localizing lesions or identifying anatomical landmarks during stereotactic studies. To be successful the examination must outline the desired area reliably while remaining safe for the patient. There is now available a variety of contrast media: negative contrast, usually air, or positive contrast, which may be either in oily solution iophendylate (Myodil) or aqueous solution meglucamine iothalamate $60 \%$ (Conray). The increasing range of targets in stereotactic surgery and the occasional need for localizing lesions in any part of the ventricular system make it unlikely that any one contrast material would be superior in all circumstances. The following study of the filling characteristics of these contrast agents, used in what proved to be normal ventriculograms, was made in an attempt to assess the suitability of each agent for the particular situation.

\section{METHOD}

Sixty normal ventriculograms which had been performed as part of routine clinical practice in the Institute of Neurological Sciences, Glasgow, between 1968 and 1971 were examined. Air, iophendyl- ate or meglucamine iothalamate $60 \%$ had been injected through a frontal burr hole in every case except one, where a parietal approach was used. A scoring system was devised for the lateral ventricle, third ventricle, aqueduct of Sylvius, and fourth ventricle to minimize the influence of the imaginative eye (Table 1).

TABLE 1

SCORING SYSTEM

\begin{tabular}{|c|c|c|c|}
\hline Site & Scores & & Total \\
\hline Lateral ventricle & $\begin{array}{l}1 \text { point } \\
\frac{1}{2} \text { point }\end{array}$ & $\begin{array}{l}\text { 1. Frontal horn } \\
\text { 2. Trigone } \\
\text { 3. Inferior horn } \\
\text { 1. Clear demonstration of } \\
\quad \text { amygdala }\end{array}$ & $3 \cdot 5$ \\
\hline 3rd ventricle & $\frac{1}{4}$ point & $\begin{array}{l}\text { 1. Filling } \\
\text { 2. Anterior commissure } \\
\text { 3. Lamina terminalis } \\
\text { 4. Optic recess } \\
\text { 5. Infundibular recess } \\
\text { 6. Anterior floor } \\
\text { 7. Posterior floor } \\
\text { 8. Posterior commissure } \\
\text { 9. Pineal recess } \\
\text { 10. Suprapineal recess } \\
\text { 11. Posterior roof } \\
\text { 12. Anterior roof }\end{array}$ & $3 \cdot 0$ \\
\hline \multirow[t]{2}{*}{$\begin{array}{l}\text { Aqueduct of } \\
\text { Sylvius }\end{array}$} & 1 point & $\left.\begin{array}{l}\text { 1. Superior } \\
\text { 2. Inferior }\end{array}\right\} \begin{array}{l}\text { segment of } \\
\text { aqueduct on } \\
\text { lateral exposure }\end{array}$ & \\
\hline & & 3. Complete AP outline & $3 \cdot 0$ \\
\hline 4 th ventricle & 1 point & $\begin{array}{l}\text { 1. Anterior medullary velum } \\
\text { 2. Posterior medullary velum } \\
\text { 3. Floor of } 4 \text { th ventricle } \\
\text { 4. Lateral recesses }\end{array}$ & $4 \cdot 0$ \\
\hline
\end{tabular}




\section{RESULTS}

Results using this scoring system are tabulated in Table 2. The maximum score is obtained by multiplying the total for the particular situation in Table 1 by the number of cases using each contrast agent (20).

It will be noted that, while Conray gives a generally good distribution, air scored only for the lateral and 3rd ventricles, while Myodil

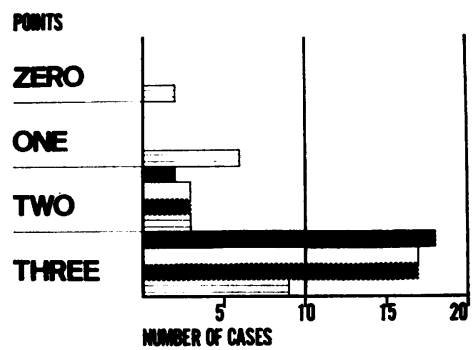

FIG. 1. Lateral ventricle score. $\square$ Ipsilateral air. Contralateral air. $\square$ Ipsilateral Conray. $⿴$ Contralateral Conray.

scored in the 3rd ventricle, aqueduct, and 4th ventricle.

LATERAL VENTRICLES Figure 1 portrays the individual case scores in points. The inferior horn did not fill in any case where one or more points were lost. The amygdala was seen 16 times with ipsilateral air, 13 times with ipsilateral Conray, 12 times with contralateral air, and only five times with contralateral Conray.

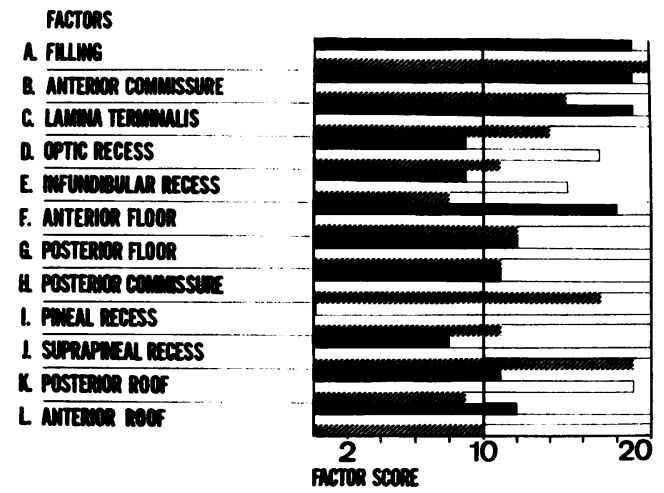

FIG. 2. Factor profile-3rd ventricle. Air. $\square$ Conray. Myodil.

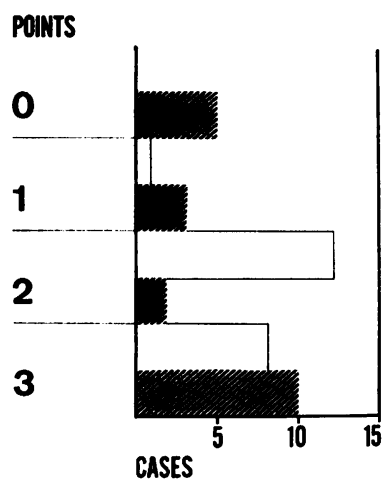

(a)

FACTORS

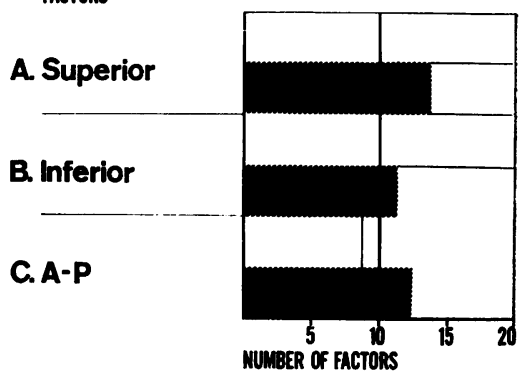

(b)

FIG. 3. (a) Aqueduct score. (b) Factor profileaqueduct. $\square$ Conray. Myodil.

THIRD VENTRICLE The individual factor scores using the triad of contrast materials are shown in Fig. 2. The AC-PC line was clearly seen on a single film in all 20 Conray studies and in 11 and seven of the air and Myodil studies respectively. The massa intermedia was noted in total in all Conray studies, whereas with air and Myodil incomplete delineation was more often the rule.

AQUEDUCT OF SYLVIUS Figures $3 \mathrm{a}$ and $\mathrm{b}$ outline the case scores and the factor profile using Myodil and Conray. Single points were given if, on lateral exposures, the superior (factor A) or the inferior part (factor B) of the aqueduct was seen. The third point was given only if both superior and inferior segments could be clearly identified on the anteroposterior (AP) view. When Conray is used, the excellent filling of the anterior recesses may make identification of the aqueduct on AP views difficult, for in the 11 cases where the aqueduct was not identified 


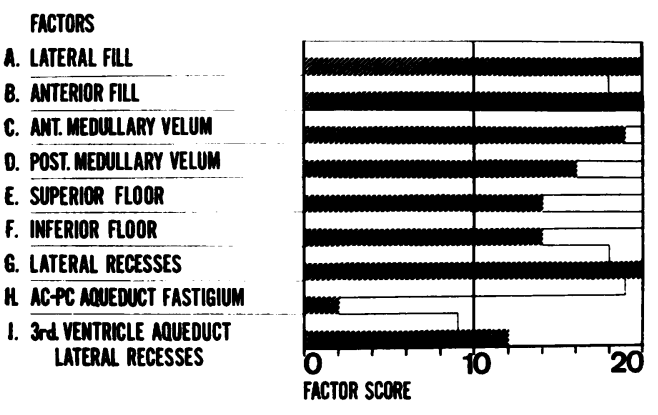

FIG. 4. Factor profile-4th ventricle. Conray Myodil.

TABLE 2

RESULTS

\begin{tabular}{lclll}
\hline Site & $\begin{array}{c}\text { Maximum } \\
\text { score }\end{array}$ & Air & Conray & Myodil \\
\hline Injected lateral ventricle & 70 & 66 & $63 \cdot 5$ & - \\
$\begin{array}{l}\text { Contralateral lateral } \\
\quad \text { ventricle }\end{array}$ & 70 & 63 & $41 \cdot 5$ & - \\
3rd ventricle & 60 & $36 \cdot 75$ & $57 \cdot 8$ & 36 \\
Aqueduct of Sylvius & 60 & - & 47 & 37 \\
4th ventricle & 80 & - & 78 & 70 \\
\hline
\end{tabular}

clearly, excellent filling of the anterior recesses occurred 10 times, whereas in the nine cases where the aqueduct was identified clearly the anterior recesses were seen well in only three when the conventional Towne's view was used. The Myodil studies achieved more perfect scores than the Conray, but there were also five cases in which a zero score was achieved. This emphasizes the difficulty in maintaining the oily contrast materials in the proper position until radiographs are taken.

FOURTH VENTRICLE The individual factor filling profiles for Myodil and Conray are presented in Fig. 4. Factors $\mathrm{H}$ and $\mathrm{I}$ were scored as positive only when the three elements were seen on a single film. The angle of the apex of the fourth ventricle is more often acute-that is, less than $50^{\circ}$-when Conray is used due to more frequent filling of the posterior superior recesses, while this angle is usually greater than $70^{\circ}$ when Myodil is employed due to filling of the dorsal median recess (the fastigium).

\section{DISCUSSION}

When the usefulness of different media is discussed in particular situations, the following matters need to be considered: the reliability of visualizing those structures which may be difficult to see due to overlap of adjacent structures, or their inherently small size with associated low levels of contrast material, or their being relatively inaccessible to a particular contrast material. The technical ease of injection and the subsequent manipulation of the patients are also a consideration. Complications, both immediate and delayed, are likewise decisive factors.

Comparative studies of contrast media for ventriculography tend not to lay sufficient emphasis on the particular requirements of this investigation in different circumstances. When pneumoventriculography held undisputed popularity the emphasis was on total visualization of the ventricular system, which often led to excessive amounts of air being used and to unduly prolonged examinations. An early criticism of small volume positive contrast ventriculography (Myodil) was that only part of the system was shown, but in many instances only part of the system is of interest-for example, stereotaxy. That is why our study has been directed at indicating the reliability of these different agents in showing different parts of the system, because no one medium would be expected to be ideal in all circumstances.

The analysis of the relative merits of water soluble contrast materials as compared with air and insoluble positive agents is not new. Walter Dandy recognized the advantages of water soluble media, but because of complications used air in his pioneer ventriculograms (Dandy, 1918). He was later of the opinion that there was absolutely no justification for using opaque material as a means of diagnosis or localization of any tumour of the brain (Dandy, 1936). However, because of inconstant filling of the axial ventricular system when air or other gases were used, Sicard and Forrestier (1922) performed the first positive contrast ventriculogram using the oil-soluble Lipiodol. The irritative properties of Lipiodol soon became apparent (Lysholm, 1935) and then Bull (1950) reported the first use of Myodil in ventriculography. The proponents of oil-soluble agents, however, found them not 
only difficult to manoeuvre, image intensification notwithstanding (Siqueira et al., 1968; Lang and Russell, 1970), but also difficult to remove and this residual contrast can interfere with further studies as well as blocking further shunting attempts. Radovici and Meller (1932) were the first to report on the intracranial use of the water-miscible Thorotrast, a stabilized colloidal suspension of thorium dioxide, but this material was abandoned because of complications (Stuck and Reeves, 1938). Water-soluble agents, being diffusible and absorbable as well as giving good contrast, have returned to favour in the form of Conray. The first Conray ventriculogram was performed in man in 1962 by Heimburger and the early reports (Campbell et al., 1964; Heimburger et al., 1966; Raimondi et al., 1969) have stimulated more wide-spread support for water-soluble agents. Those who have used it have been enthusiastic, both for the general and stereotactic purpose (Handa and Handa, 1969; Picaza et al., 1970). Only two years after its introduction at this Institute, Conray is already the medium of choice in about $80 \%$ of all ventriculograms (Steven, 1972).

In our study, no one agent was shown to have a clear superiority for all situations. These ventriculograms were normal and did not show pathology, but this does not mean that panventriculography was attained nor can it be assumed that an attempt to attain complete filling was made by the neuroradiologist, for this is not the policy at this Institute. The interpretation of these results should accept the positive achievement of the individual contrast agent and not their individual failure, for it is clear that total replacement of cerebrospinal fluid with air, Myodil, or Conray would each show pan-ventricular filling, although details will vary depending on the agent employed. Bearing this in mind, although water-soluble Conray achieved pan-ventricular filling, air was restricted to the lateral and third ventricles, while Myodil lay in the lateral ventricles only by mischance.

While neither air nor Conray achieved a superiority for filling of the injected lateral ventricle, the poor filling of the contralateral ventricle using Conray is in keeping with Heimburger et al. (1966), who noted that the contralateral ventricle may not fill in the normal situation, particularly when less than $5 \mathrm{ml}$
Conray $60 \%$ before dilution, the recommended maximum, is used. Air would appear to be the contrast medium of choice to establish communication between the ventricles, and also when $\widehat{\theta}$ bilateral representation of the amygdala is desired. The hazards of air when there is increased intracranial pressure should not be minimized even with small volume replacements. and in these situations, when ipsilateral ventricu- $\vec{F}$ lar masses are suspected, Conray is equally $\frac{\text { }}{0}$ effective and less upsetting.

Third ventricular filling, both from a global $\frac{\bar{D}}{\bar{D}}$ and focal view, is clearly superior with Conray. $\frac{\mathbb{Q}}{2}$ The greater diffusion of the water-soluble substance results in greater ease in demonstrating the AC-PC line (anterior to posterior commissure) and the more precise definition of the $\vec{\omega}$ smaller recesses, such as the optic infundibular, pineal and suprapineal recesses. However, the anterior recesses may not be shown by Conray, $\dot{\omega}$ and failure in these instances is due either to ing sufficient concentration or to the presence of small air locks. Direct catheterization of tiec third ventricle, as described by Asambuja et 9 을 (1956) and recommended by Handa and Hand (1969), is not needed using the technique Steven (1972), thus minimizing the added dange of perforating the structures of the third veaptricle and allowing an escape of Conray into the subarachnoid space, which will perhaps mar the study and also increase the chance of reactions.

The aqueduct of Sylvius is seen best in the lateral views with Conray and usually in concert with the third and fourth ventricles. AP representation is less reliable when Conray persists in the forward midline structures, thus obliterating the image of more posterior structures lying in the same sagittal plane, and Myodil, being less likely to persist anteriorly, proves superior in this regard. Conray, being diffusible as well as:flowing by gravity, is the medium of choice for outlining the aqueduct on the lateral view and $\delta$ would be acceptable if the anterior recesses are $₹$ emptying for view on the AP, thus reserving 을 Myodil for any failures.

Fourth ventricular filling is a strong feature in favour of both Conray and Myodil, maintaining N a similar but less marked lateral-AP orientation $N$ as seen with the aqueduct. The quality of con-N trast of the diffusible agent is decreased with its ${ }_{\sigma}^{\omega}$ greater dilution at the fourth ventricle, while the 
quality of contrast with Myodil remains constant. Attempts at overcoming this deficiency with Conray increases the concentration of Conray over the area postrema in the floor of the fourth ventricle and increases the risk of the spill into the subarachnoid space with accompanying complications. Further, complete filling of the fourth ventricle with the insoluble material leads to difficulty in its removal which may block future shunting procedures. The contour of the fourth ventricle seen with air or Myodil usually depicts the dorsal median recess, which is also known as the 'fastigium'. When the watersoluble materials are used, filling of the posterior superior recesses occurs to a greater extent with subsequent alteration of contour. These posterior superior recesses course above and behind the posterior medullary velum and the roof nuclei-fastigium, emboliform, and globosumlie above its superior border. It is important to recognize this variation when the 'fastigium' is being used for stereotactic purposes (Ferguson and Turner, 1973).

There are certain complications of ventriculography which must be considered whatever medium is used. The burr hole and ventricular catheterization may precipitate infection or haemorrhage in the normal subject, and may be further complicated by an unplanned puncture of cyst, abscess, neoplasms, or vascular malformation in the abnormal. Inadvertent injection of the contrast material into the subarachnoid space may prevent the identification of normal structures, as when air in the suprasellar space blocks the anterior recesses, and may lead to an increase in reactions when the positive contrast materials reach the subarachnoid space. While the difficulties of using air in cases with increased intracranial pressure are circumvented to some extent when Conray is the agent, severe toxic reactions with this material have been reported and utilization of no more than $5 \mathrm{ml}$. of undiluted Conray 60 is recommended (Heimburger et al., 1966). Premedication with anti-emetic and anti-epileptic drugs may also be of use (Raimondi et al., 1969). Resuscitation equipment should be on hand when Conray is used (Picaza et al., 1970).

Complications in this group of patients were limited to headache and vomiting and were not significantly different for any of the three materials.

\section{CONCLUSION}

In this study, Conray proved to be as good or better than either of the other two agents for visualizing the injected lateral ventricle, the third ventricle, the aqueduct of Sylvius on lateral exposure, and the fourth ventricle. Air was the most reliable for the non-injected lateral ventricle, while Myodil proved superior for identification of the aqueduct on the AP view. We feel this study suggests that the role of the clinician, rather than being minimized by the refinements of neuroradiology, is to be emphasized; for only with accurate clinical definition of a patient's problem will the decision to perform ventriculography and the use of the most appropriate contrast agent be made in the patient's best interest.

I should like to acknowledge the cooperation and advice of Dr. Leslie Steven, Department of Neuroradiology; Mr. John Turner, consultant neurosurgeon, who prompted the investigation by his interest in delineating stereotaxic targets; and Professor W. B. Jennett who reviewed the manuscript.

\section{REFERENCES}

Asambuja, N., Arana Iniguez, R., Sande, M. T., and García Güélfi, A. (1956). Central ventriculography. Acta Neurologica Latinoamericana, 2, 58-64.

Bull, J. W. D. (1950). Positive contrast ventriculography. Acta Radiologica. Diagnosis, 34, 253-268.

Campbell, R. L., Campbell, J. A., Heimburger, R. F., Kalsbeck, J. E., and Mealey, J., Jr. (1964). Ventriculography and myelography with absorbable radiopaque medium. Radiology, 82, 286-289.

Dandy, W. E. (1918). Ventriculography following the injection of air into the cerebral ventricles. Annals of Surgery, 68, 5-11.

Ferguson, L., and Turner, J. W. Objective definition of the fastigium and posterior superior recess of retzius. Submitted to Journal af Neurosurgery, December 1973.

Handa, J., and Handa, H. (1969). Methylglucamine iothalamate 60 per cent for cerebral ventriculography. American Journal of Roentgenology, 107, 631-636.

Heimburger, R. F., Kalsbeck, J. E., Campbell, R. L., and Mealey, J., Jr. (1966). Positive contrast cerebral ventriculography using water-soluble media. Journal of Neurology, Neurosurgery, and Psychiatry, 29, 281-290.

Lang, E. K., and Russell, J. R. (1970). Pantopaque ventriculography: demonstration and assessment of lesions of the third ventricle and posterior fossa. Journal of Neurosurgery, 32, 5-15.

Lysholm, E. (1935-37). Das Ventrikulogramm. Acta Radiologica. Diagnosis, Suppl. 24-26. 
Picaza, J. A., Hunter, S. E., and Cannon, B. W. (1970). Axial ventriculography. Journal of Neurosurgery, 33, 297303.

Radovici, A., and Meller, O. (1932). Essai de liquidographie céphalo-rachidienne. Encéphalo-myélographie par le thorotrast sous-arachnoïdien. Bulletin de l'Académie de Médecine, 107, 314-317.

Raimondi, A. J., Samuelson, G. H., and Yarzagaray, L. (1969). Positive contrast (Conray 60) serial ventriculo- graphy in the normal and hydrocephalic infant. Annales de $Z$ Radiologie, 12, 377-392.

.Siqueira, E. B., Bucy, P. C., and Cannon, A. H. (1968). Positive contrast ventriculography, cisternography and myelography. American Journal of Roentgenology, 104, 132-138.

Steven, J. L. (1972). Personal communication.

Stuck, R. M., and Reeves, D. L. (1938). Dangerous effects of thorotrast used intracranially. Archives of Neurology and Psychiatry, 40, 86-115. 